\title{
Composite material based on andesite of Transcarpathia
}

\author{
L.I. Melnyk (ORCID 0000-0001-5139-3105), L.P. Chernyak (ORCID 000-0001-8479-0545), O.V. Kozlovets
}

National Technical University of Ukraine "Igor Sikorsky Kyiv Polytechnic Institute”, av. Peremogy, 37, Bldg. 21, Kyiv, 03056, Ukraine

Tel.: +380637238179, +380672985775,+380685137118

E-mail:luba_xtkm@ukr.net,lpchernyak@ukr.net,okozlovets@icloud.com

Article info: received 07.09.2020, revised 15.09.2020, accepted 30.09.2020

Melnyk, L.I., Chernyak, L.P., Kozlovets, O.V. (2020) Composite material based on andesite of Transcarpathia 3(48), doi: $10.26909 /$ csl.3.2020.2

Composite materials for various purposes are made on the basis of initial mixtures of fillers and bonding components. The varieties of these components and their quantitative ratio determine the qualitative indicators of the composite. This causes rosettes of the raw material base for the production of composites, including the use of by-products of mineral extraction, which meets the objectives of resource saving.

This paper presents the results of the study of composite materials on the basis of by-products of extraction of igneous rocks of Transcarpathia - siftings of andesite as a filler and copolymer Latex 2012 as a matrix. The analysis of chemical and mineralogical composition of andesite siftings from Khust quarry was carried out.

An analysis of the dependence of the main physical and mechanical characteristics of the studied composites on the concentration of andesite in the range of $55-85 \mathrm{wt}$. \% and of the corresponding change in the quantitative ratio of filler and copolymer is performed. Differences in parameters using andesite samples with different particle size distribution (the poly-fractional with particle size $<3 \mathrm{~mm}$ and the dispersion one with particle size $<0.5 \mathrm{~mm}$ ) were determined.

The peculiarities of the formation of the pore structure of the composite material obtained using andesite samples of different granulometry connected with the increasing degree of dispersion associated with the increase in the number of filler particles in the composite, increasing adhesion forces in the copolymer-filler system and increasing of surface energy of andesite particles are shown.

The possibility of increasing the abrasive resistance of the composite material when using the initial mixture based on the andesite-copolymer system has been experimentally confirmed.

Key words: composite, filler, andesite, concentration, granulometry, polymer matrix, porosity, properties.

\section{Композиційний матеріал на основі андезиту Закарпаття}

\author{
Л.І. Мельник, Л.П. Черняк, О.В. Козловець
}

Національний технічний університет Украӥни “Київський політехнічний інститут імені Ігоря Сікорського”, Київ, Украӥна

Композиційні матеріали різних напрямків призначення виготовляють на основі вихідних сумішей армуючого (наповнювача) та в'яжучого компонентів. Різновиди цих компонентів та їх кількісне співвідношення визначають якісні показники композиту. Це обумовлює розвиток сировинної бази виробництва композитів, в тому числі із використанням супутніх продуктів видобутку мінеральної сировини, що відповідає задачам ресурсозбереження.

В даній роботі подано результати дослідження композиційних матеріалів на основі супутніх продуктів видобутку магматичних порід Закарпаття - відсівів андезиту, як наповнювача та сополімеру Latex 2012, як матриці. Проведено аналіз хімічного та мінералогічного складу відсівів андезиту Хустського кар'єру.

Проведено аналіз залежності основних фізико-механічних характеристик досліджуваних композитів від концентрації андезиту в інтервалі 55 - 85 мас. \% та відповідної зміни кількісного співвідношення наповнювача та сополімеру. Визначено відмінності у показниках при використанні проб андезиту різного гранулометричного складу: поліфракційного з розміром частинок $<3$ мм та дисперсного з розміром частинок $<0,5$ мм. 
Показано особливості утворення порової структури композиційного матеріалу, отриманого з використанням проб андезиту різної гранулометрії, що при збільшенні ступеню дисперсності пов’язується із зростанням у композиті числа контактів частинок наповнювача, із зростанням сил адгезії у системі сополімер-наповнювач при збільшенні вільної енергії поверхні частинок андезиту.

Експериментально підтверджено можливість підвищення абразивної стійкості композиційного матеріалу при застосуванні вихідної суміші на основі системи андезит-сополімер.

\section{ВстуII}

Розвиток науково-технічних засад технології полімерних композиційних матеріалів є предметом численних досліджень $[1,2]$. Визнано значну роль наповнювачів композитів, використання яких дозволяє суттєво зменшити кількість необхідних полімерів - в'яжучих, та підвищити властивості матеріалів [3].

Як дисперсні наповнювачі, головним чином, застосовуються природні матеріали - крейда, каолін, графіт [4, 5]. Одним із напрямків розширення сировинної бази наповнювачів стали роботи по вивченню та використанню порід вулканічного походження різних родовищ [6 - 8]. В цьому зв'язку привертають увагу розробки щодо застосування андезиту як наповнювача в композиційних матеріалах, в тому числі будівельних [9 - 11].

Відповідно до положення сучасного матеріалознавства про зв'язок склад $\rightarrow$ структура $\rightarrow$ властивості характеристики композитів залежать від різновидів наповнювача і матриці, технології та параметрів виготовлення. При цьому ступінь зв'язку компонентів, їх концентрація та рівномірність об'ємного розподілу визначають параметри структури, загальні фізико-механічні та спеціальні властивості композитів.

При застосуванні як наповнювача сировини різного генезису, в тому числі супутніх продуктів та відходів виробництва, 3'являється можливість комплексного вирішення питань якості композитів і екології. В цьому зв'язку серед природної сировини привертають увагу відходи нерудної промисловості - відсіви видобутку та подрібнення магматичних порід, зокрема андезиту.

Мета роботи. Розробки по застосуванню андезиту потребують урахування особливостей його фізико-хімічного складу як фактору впливу на характеристики досліджуваних систем і властивості продукту виробництва. Це стало метою даної роботи стосовно композитів на основі андезиту з полімерним в'яжучим.

\section{Матеріали та методи дослідження}

Об'єктом дослідження стали композиційні матеріали на основі системи сополімер-відсіви андезиту при варіюванні концентрації наповнювача.
Методика роботи передбачала поєднання фізико-хімічних методів аналізу сировини та композитів на іiі основі з технологічними тестуваннями властивостей матеріалу:

- аналіз хімічного складу сировинних компонентів за стандартними методиками;

- рентгенофазовий аналіз (порошковий препарат) за допомогою дифрактометру ДРОН-3М (випромінювання $\mathrm{Cu} \mathrm{K \alpha} \mathrm{1-2,} \mathrm{напруга} 40 \mathrm{kV}$, струм $20 \mathrm{~mA}$, швидкість 2 град/хв.);

- абразивну стійкість зразків визначали у відповідності до ДСТУ Б.В.2.7-212:2009 на крузі стирання типу Беме;

- механічні властивості, визначали на випробувальній машині TIRAtest-2151.

Як в'яжучий компонент використовували різновид сополімерів - водну дисперсію стирол-бутадієнову марки Latex 2012 (табл. 1), хімічний склад якого характеризується сполученням із стиролом $\left(\mathrm{C}_{6} \mathrm{H}_{5}-\mathrm{CH}=\mathrm{CH}_{2}\right)$ у випадку Latex 2012 бутадієну $\left(\mathrm{CH}_{2}=\mathrm{CH}-\mathrm{CH}=\mathrm{CH}_{2}\right)$.

Таблиця 1.

Характеристики сополімеру

\begin{tabular}{|l|c|}
\hline \multirow{2}{*}{ Показники } & Сополімер \\
\cline { 2 - 2 } & Latex 2012 \\
\hline Хімічний склад & Стирол-бутадієн \\
\hline Вміст стиролу, \% & 30 \\
\hline Фізичний стан & $\begin{array}{c}\text { Водна дисперсія } \\
\text { білого кольору }\end{array}$ \\
\hline Вмістом сухого залишку, $\%$ & 51.0 \\
\hline Розмір часток, нм & 140 \\
\hline В'язкість, МПа•с & 200 \\
\hline рН & 5.5 \\
\hline Температура (МТПУ), ${ }^{\circ} \mathrm{C}$ & $<5$ \\
\hline
\end{tabular}

Як наповнювачі використовували відсіви андезиту Хустського кар'єру Закарпатської області. За хімічним складом проба відсівів андезиту характеризується підвищеним вмістом $\mathrm{SiO}_{2}$ при кількісному співвідношенні $\mathrm{SiO}_{2}: \mathrm{Al}_{2} \mathrm{O}_{3}=3,5$, оксидів заліза, лужноземельних і лужних оксидів типу $\mathrm{RO}+\mathrm{R}_{2} \mathrm{O}=$ 11,47 мас. \% (табл. 2). 


\section{Результати та їх обговорення}

За мінералогічним складом проба відсівів андезиту як різновид магматичних порід характеризується розвиненими кристалічними фазами, розподіленими у склофазі (рис. 1).

Технологія виготовлення композиту на основі системи сополімер-наповнювач складалась 3 послідовного виконання наступних операцій:

- механоактивація наповнювача і в'яжучого в кульовому млині (20 хвилин);

- визрівання композиції (48 годин при кімнатній температурі);
- виготовлення заготовок (дозування наважок масою 5,0 г та закладання їх у форми);

- термообробка заготовок (поступове підвищення температури та витримка 1 година при $80{ }^{\circ} \mathrm{C}$ );

- пресування (P = $10 \mathrm{MПа)} \mathrm{зразків} \mathrm{циліндричної}$ форми з діаметром 16 мм.

В даній роботі досліджено системи з сополімером Latex 2012 як в'яжучим при диференціації гранулометрії та концентрації андезиту як наповнювача. При цьому використовували проби Аф поліфракціонованого андезиту та Ам2 із тонкодисперсними частинками розміром $<0,5$ мм (табл. 3).

Таблиця 2.

Хімічний склад наповнювача

\begin{tabular}{|c|c|c|c|c|c|c|c|c|c|c|}
\hline \multirow{2}{*}{ Назва проби } & \multicolumn{10}{|c|}{ Вміст оксидів, мас. \% } \\
\cline { 2 - 11 } & $\mathrm{SiO}_{2}$ & $\mathrm{Al}_{2} \mathrm{O}_{3}$ & $\mathrm{Fe}_{2} \mathrm{O}_{3}$ & $\mathrm{TiO}_{2}$ & $\mathrm{CaO}$ & $\mathrm{MgO}$ & $\mathrm{SO}_{3}$ & $\mathrm{Na}_{2} \mathrm{O}$ & $\mathrm{K}_{2} \mathrm{O}$ & в.п.п \\
\hline Андезит & 59,70 & 16,97 & 8,42 & 0,72 & 5,76 & 1,21 & - & 2,68 & 1,82 & 1,11 \\
\hline
\end{tabular}

Таблиця 3.

Гранулометричний склад андезиту

\begin{tabular}{|c|c|c|c|c|c|}
\hline \multirow{2}{*}{ Код проби } & \multicolumn{5}{|c|}{ Вміст фракцій матеріалу (мм), \% } \\
\cline { 2 - 6 } & $3-2$ & $2-1$ & $1-0,5$ & $0,5-0,2$ & $<0,2$ \\
\hline Аф & 10 & 20 & 25 & 25 & 20 \\
\hline Ам2 & - & - & - & \multicolumn{2}{c|}{100} \\
\hline
\end{tabular}

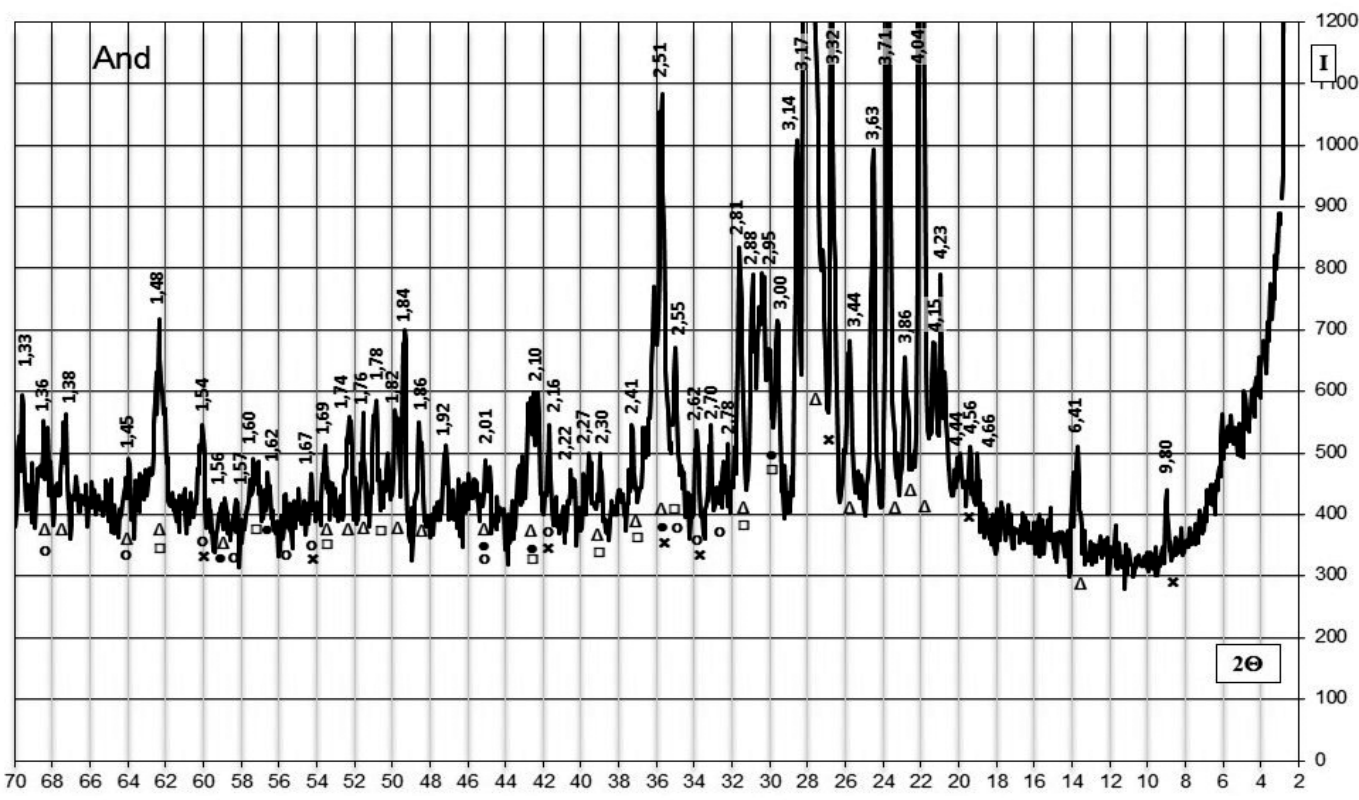

Рис. 1. Дифрактограма проби андезиту.

Позначення: $\Delta$ - олигоклаз-андезин, $\bullet$ - авгіт, $\square-$ магнетит, о - рогова обманка, $\mathrm{x}$ - біотит 
Як свідчать результати випробувань показники фізико-механічних властивостей композиту суттєво залежать від співвідношення концентрації наповнювача - андезиту. При цьому із збільшенням концентрації наповнювача спостерігається загальна закономірність зростання густини та зменшення водопоглинання. Разом із тим, показники вказаних властивостей залежать від гранулометрії наповнювача.

Так, при використанні дисперсного андезиту Ам2 у порівнянні з поліфракціонованим Аф зразки композиту характеризуються більшим водопоглинанням - 8,8 - 2,1 проти 5,6 - 1,8 \% та меншою гус-

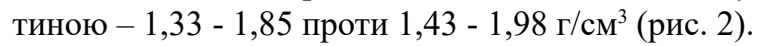

Структурні відмінності дослідних зразків композиту визначаються характеристиками порової структури. За розрахунками на основі результатів тестувань встановлено, що при використанні дисперсного андезиту у порівнянні з поліфракційним має місце зменшення загальної та відкритої пористості (табл. 4).
Відзначене при використанні дисперсного андезиту зменшення кількості та питомої частки відкритих пор пов'язується:

- із зростанням у композиті числа контактів частинок наповнювача [12];

- із зростанням у композиті сил адгезії [13] у системі сополімер-наповнювач при збільшенні дисперсності та, відповідно, вільної енергії поверхні частинок андезиту.

Вказані структурні відмінності обумовлюють визначені фізико-механічні (густину, водопоглинання, модуль пружності) та експлуатаційні (стиранність) показники властивостей композиційного матеріалу на основі закарпатського андезиту.

\section{Висновки}

1. Встановлено особливості введення до складу композиційних матеріалів відсівів андезиту як наповнювача в кількості 55 - 85 мас. \% при використанні сополімеру Latex 2012 як матриці.

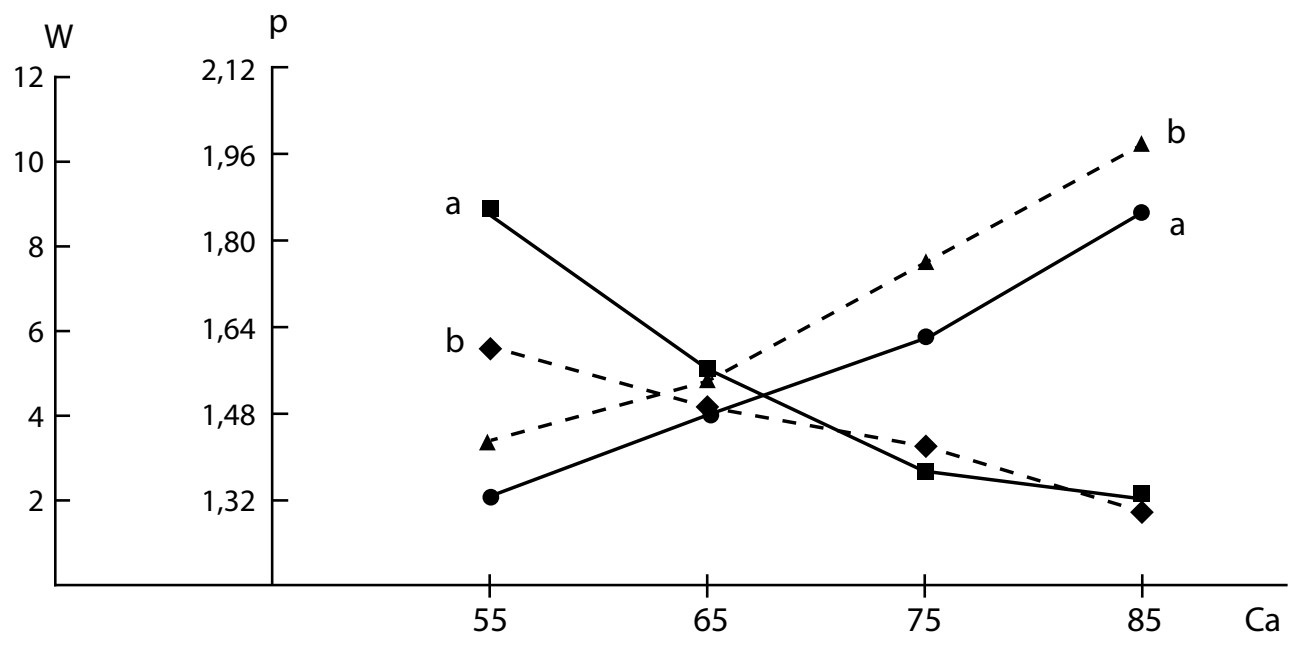

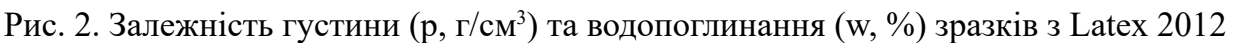
від концентрації андезиту Аф (a) і дисперсного Ам2 (b)

Таблиця 4.

Характеристики зразків композиту

\begin{tabular}{|l|c|c|}
\hline \multirow{2}{*}{ Параметри } & \multicolumn{2}{c|}{ Композит 3 андезитом } \\
\cline { 2 - 3 } & Аф & Ам2 \\
\hline Загальна пористість, \% & $11,8-4,0$ & $-3,4$ \\
\hline Відкрита пористість, \% & $8,8-2,4$ & $5,4-1,8$ \\
\hline Питома частка відкритих пор & $0,74-0,60$ & $0,69-0,53$ \\
\hline Стиранність, г/см ${ }^{2}$ & $0,01-0,02$ & $0,005-0,015$ \\
\hline Модуль пружності, $E$, Па/мм & $57-72$ \\
\hline
\end{tabular}


2. Визначено відмінності хіміко-мінералогічного складу та гранулометрії відсівів Закарпатського андезиту як факторів впливу на показники фізико-механічних і експлуатаційних властивостей композиту.

3. Розглянуто вплив концентрації та гранулометичного складу андезиту на порову структуру та властивості композиту з полімерною матрицею. При цьому відмічено можливість підвищення абразивної стійкості отриманого матеріалу.

\section{References}

1. Melnyk, L. Research of electrical properties of epoxy composite with carbon fillers. Technology audit and production. - 2017. - V. 3(1/35). - P. 1539 - 1641.

2. Suprakas Sinha Ray, Masami Okamoto. Polymer/ layered silicate nanocomposites: a review from preparation to processing. Progress in Polymer Science. 2003. - V. 28. - Is. 1(35). - P. 4 - 10.

3. Sokolov, I.I., Troshkin, I.V. Effect of the Chemical Nature of Fabric Mineral Fillers on the Properties of Polymer Composite Materials. Glass and Ceramics. 2016. - V. 73. - Is. 5 - 6. - P. 231 - 233.

4. Rothon, R.N. Particulate fillers for polymers. Rapra Rev. Rep. - 2001. - P. 12:16 - 17.

5. Мельник, Л.І. Закономірності формування і застосування термостійких струмопровідних силоксанграфітових матеріалів. Автореферат дисертації. 2009. -22 c.
6. H. Kuno. Origin of andesite and its bearing on the Island arc structure. Bulletin Volcanologique. - 1968. Vol. 32. - P. 141 - 176.

7. S.S. Sarkar, S.K. Nag, S. Basu Mallik. The origin of andesite from Rajmahal traps, eastern India: A quantitative evaluation of a fractional crystallization model. Journal of Volcanology and Geothermal Research. 1989. - Vol. 37. - Is. 3 - 4. - P. 365 - 378.

8. Черняк, Л.П. Структурні зміни та властивості магматичних порід Західної України. Керамика: наука и жизнь. - 2016. - № 4(33). - С. 4 - 12.

9. Ismail Uzun, Serdal Terzi. Evaluation of andesite waste as mineral filler in asphaltic concrete mixture / Construction and Building Materials. - 2012. - Vol. 31.P. 284 - 288.

10. Самошина, Е.Н., Шитова, И.Ю. Выбор наполнителя для получения химически стойкого композита на основе серного вяжущего. Фундаментальные исследования. - Пенза: Изд. Дом «Академия Естествознания». - 2016. - № 4 - 1. - С. 107 - 111.

11. Ulku Soydal, Suheyla Kocaman, Mustafa Esen Marti, Gulnare Ahmetli. Study on the reuse of marble and andesite wastes in epoxy-based composites Polymer Composites. - 2018. - Vol. 39. - Is. 9. - P. 3081 - 3091.

12. Физико-химическая механика дисперсных минералов. С.П. Ничипоренко, Н.Н. Круглицкий, А.А. Панасевич, В.В. Хилько; под общ. ред. С.П. Ничипоренко. - К.: Наукова думка. - 1974. - 246 с.

13. Б.В. Дерягин, Н.А. Кротова, В.П. Смилга. Адгезия твердых тел. - М.: Наука. - 1973. - 280 с. 